\title{
Is there a greater risk of dying in a car crash when other passengers are unrestrained?
}

Cummings P, Rivara FP. Car occupant death according to the restraint use of other occupants: a matched cohort study. JAMA 2004;291:343-9.

Background: The direct benefit from wearing a seatbelt when travelling in an automobile is uncontestable and has resulted in laws making the use of seatbelts mandatory. It is uncertain if the risk of injury to a passenger is increased if other passengers in the same vehicle are unrestrained - that is, if unrestrained occupants become projectiles at the time of a crash.

Design: In a database analysis of fatal car crashes throughout the United States between 1988 and 2000, investigators evaluated the risk of dying when there was another occupant in the car who might act as a projectile. Each person in the car was considered a target if there was another occupant, whether or not that occupant was wearing a restraint. To control for crash characteristics, pairs of occupants were compared to a third person in the same vehicle, who served as a control. Relative risks for death were calculated for target occupants seated in all positions of the vehicle relative to other passengers in the vehicle.

ลิ

Results: The authors report

1113 traffic crashes in which

gु there was a driver and a front ô seat passenger, both of whom were wearing seatbelts, and a po$\ddot{-}$ tential projectile occupant in the @back seat who was not wearing a seatbelt. (The total of 1113 is calculated from the numbers presented in the third line of Table 4 of the study.) In this configuration of occupants, we calculated that the target died in 739 crashes, the control occupant died in 564 crashes and both target and control occupant died in 190 crashes. We also calculated that this yielded a relative risk of death for target passengers when other occupants were unrestrained of about 1.31 (739/564) (95\% confidence interval 1.17-1.46), which persisted after statistical adjustments for selected characteristics and seating configurations. The risk ratios for death of target occupants reported in the study are summarized in Table 1.

Commentary: The results are intuitively appealing, yet they might overstate the association. Specifically, the nonrandomized seating arrangement of the occupants in the vehicles might have allowed uncontrolled factors to confound the analyses (e.g., the majority of front-seat targets were women, who are known to be more likely than men to die when hit by the same physical forces). Additionally, the pair-matching in this study allowed the same person to appear in multiple analyses and thereby created a false consistency in the results.
Table 1: Adjusted risk ratios for death of a target occupant in a car crash

\begin{tabular}{|c|c|c|}
\hline Target (restrained) & Other occupant & $\begin{array}{l}\text { Risk ratio of death } \\
\text { of target }(95 \% \mathrm{Cl})^{*}\end{array}$ \\
\hline Front seat & Rear seat & $1.20(1.10-1.31)$ \\
\hline Rear seat & Front seat & $1.22(1.10-1.36)$ \\
\hline Front or back & Beside & $1.15(1.08-1.22)$ \\
\hline
\end{tabular}

The investigators deserve congratulations for using a pairmatched design to tackle realworld driving. The results, as they acknowledge, conflicted with other studies on the indirect effectiveness of seatbelts for other passengers. Perhaps the results are a bit too good, given current estimates of the direct effect of seatbelts that suggest a $40 \%-45 \%$ reduction in risk of death for the user. ${ }^{1}$ For perspective, airbags offer about a $20 \%$ reduction in risk, ${ }^{2}$ and a speeding ticket offers, on average, about a $35 \%$ reduction in risk for 1 month for the driver. ${ }^{3}$

Practice implications: This study is welcome news for policymakers in Canada wishing to expand current seatbelt laws and those in the United States wishing to enact seatbelt laws. Clinicians who focus on prevention can also refer to this study when recommending seatbelt use, since motor vehicle trauma is the leading cause of death of Canadians between the ages of 1 and 41 . No contraindications to using seatbelts have been found, and the current study provides one more reason to encourage their use. Just as we caution those whose behaviour can be harmful to others through secondhand smoke, car drivers and passengers should insist that all occupants buckle up.

\section{Donald A. Redelmeier \\ Harriette G. C. Van Spall \\ Division of General Internal \\ Medicine \\ Sunnybrook and Women's College \\ Health Sciences Centre \\ Toronto, Ont.}

\section{References \\ 1. Evans L. Traffic safety and the driver. New York: Van Nostrand Rein- hold;1991. p. 219-39. \\ 2. Evans L. Traffic safety and the driver. New York: Van Nostrand Rein- hold;1991. p. 239-43. \\ 3. Redelmeier DA, Tibshirani RJ, Evans L. Traffic-law enforcement and risk of death from motor-vehicle crashes: case-crossover study. Lancet 2003;361: 2177-82.}

